\title{
USING PARTICIPATORY APPROACH TO IMPROVE AVAILABILITY OF SPATIAL DATA FOR LOCAL GOVERNMENT
}

\author{
T. Kliment ${ }^{\mathrm{a}, \mathrm{c}}$, V. Cetl. ${ }^{\mathrm{a}}, \mathrm{H}$. Tomič ${ }^{\mathrm{a}}$, J. Lisiak ${ }^{\mathrm{b}}$, M. Kliment ${ }^{\mathrm{c}}$ \\ a University of Zagreb, Faculty of Geodesy, Kačićeva 26, HR-10 000 Zagreb, Croatia - (tkliment, vcetl, htomic)@geof.hr \\ b The city of Požega, Trg Sv. Trojstva 1, 34000 Požega, Croatia - josip.lisiak@pozega.hr \\ c Slovak University of Agriculture in Nitra, Horticulture and Landscape Engineering Faculty, Tulipánová 7, 94976 Nitra, Slovakia - \\ marcel.kliment@uniag.sk
}

KEY WORDS: Authoritative Geospatial Data, Participatory Approach, Local SDI, Web and Mobile GIS.

\begin{abstract}
:
Nowadays, the availability of authoritative geospatial features of various data themes is becoming wider on global, regional and national levels. The reason is existence of legislative frameworks for public sector information and related spatial data infrastructure implementations, emergence of support for initiatives as open data, big data ensuring that online geospatial information are made available to digital single market, entrepreneurs and public bodies on both national and local level. However, the availability of authoritative reference spatial data linking the geographic representation of the properties and their owners are still missing in an appropriate quantity and quality level, even though this data represent fundamental input for local governments regarding the register of buildings used for property tax calculations, identification of illegal buildings, etc. We propose a methodology to improve this situation by applying the principles of participatory GIS and VGI used to collect observations, update authoritative datasets and verify the newly developed datasets of areas of buildings used to calculate property tax rates issued to their owners. The case study was performed within the district of the City of Požega in eastern Croatia in the summer 2015 and resulted in a total number of 16072 updated and newly identified objects made available online for quality verification by citizens using open source geospatial technologies.
\end{abstract}

\section{INTRODUCTION}

Local governments at the municipality level make policy decisions directly affecting citizens' life on a daily basis. The geospatial information (GI) resources play a crucial role assisting local governments in various activities as urban planning, environmental monitoring, local tax obligations linked to real estate ownerships (property tax declaration), risk management, among others (Miranda et al, 2011).

The availability of authoritative spatial data has increased in the last decade due to ongoing regional (e.g. INSPIRE Infrastructure for Spatial Information in European Community), national (e.g. NSDI - National Spatial Data Infrastructure in Croatia) and local activities related to establishing of a Spatial Data Infrastructure (SDI) (Nebert, 2009).

However, there are only few examples of having organized spatial data in a "SDI like", thus interoperable and usable way on the local level in Croatia (e.g. Zagreb SDI (Šiško et al, 2012)). On the other hand, some of the spatial data required for decision making made by local government (administration) are not meant to be produced on the national level. Spatial data need to be collected / managed / verified by local resources most ideally with some community support with currently emergent practices as participatory GIS (Erik de Man, 2006) and voluntary geographic information (VGI) (Miranda et al, 2011).

In the current situation, the significant number of local governmental information infrastructures still lacks the high quality spatial data normally made available from the authoritative bodies on a national level (geodetic, mapping, environmental, agricultural, etc. agencies) due to various reasons. Today the traditional techniques of data gathering are still in use, however the frequency and diversity of updates requires to maintain the local government GI up to date. This can easily become an unfeasible task from human, technical and financial perspective. Therefore, participatory GIS approaches used to collect spatial data in order to update the property systems deployed as local SDI can considerably support decisions of a local government.

These days, the academy mostly plays a role of educator and at the same time could be seen a professional supporter of public administration bodies. The later often lacks resources and related expertise to produce spatial data, thus outsourcing the work to academia is an optimal solution. Actually, this is one of the cornerstones of a knowledge based economy where the appropriate management of the relationship between the state executive bodies on local level and academy institutions is vital to a strong and dynamic future for these institutions (George, 2006).

In addition, the citizens as volunteers produce voluntary geographic information (VGI) (Coleman et al, 2009) by gathering, revising and augmenting GI stored and made available online via a local SDI and related Web based and / or mobile applications. On the global level, there has been an explosion of interest in using the Web to collect and share GI provided voluntarily by peoples within the projects as Wikimapia and OpenStreetMap (Goodchild, 2007). Nevertheless, only a few number of current research works reported usage of VGI on a local SDI level, even though the most important and unique GI citizens can provide are related to their individual interest.

Finally, the last decade has shown that available open source geospatial technologies can provide effective, efficient and affordable way to provide interfaces between local governments and citizens taking into consideration available resources on both sides.

The main objective behind the current research was to develop a methodology and perform its pilot implementation aiming at calculations of buildings features areas based on more accurate authoritative geospatial data, participatory field observations, open source Web GIS components and interfaces and data validation performed by VGI provided by citizens, thus property owners and tax payers. In this research we simulated VGI by 
students who were collecting the data in the field. It is expected that in the future these tasks might be performed by citizens.

The present paper is structured as follows: i.) the methodology section describes the steps taken to deliver the final products / outputs; ii) the results section reports the datasets developed from calculations of new areas derived from geometries of spatial features available in authoritative dataset and extended by information from the field works, web GIS client deployed for citizens in order to display the final datasets and verify the quality. iii) The last section concludes the research and draws future directions improving the final products as well as recommends steps to be considered by other local governments demanding to establish an SDI supporting their strategic decisions.

\section{MATERIALS AND METHODS}

Constructed by the main goal of the research study, the methodology consisted of the following steps (Figure 1): i) analysis of the data available from the local SDI and authoritative data available from state geodetic administration (input data); ii) harmonization of input data based on gap analysis and identified improvement requests; iii) data collection; iv) data processing v) new database modelling and integration of input / processed data, raw field observations and user needs identified for the final system, vi) authorized data publication and verification based on open source GI technologies.

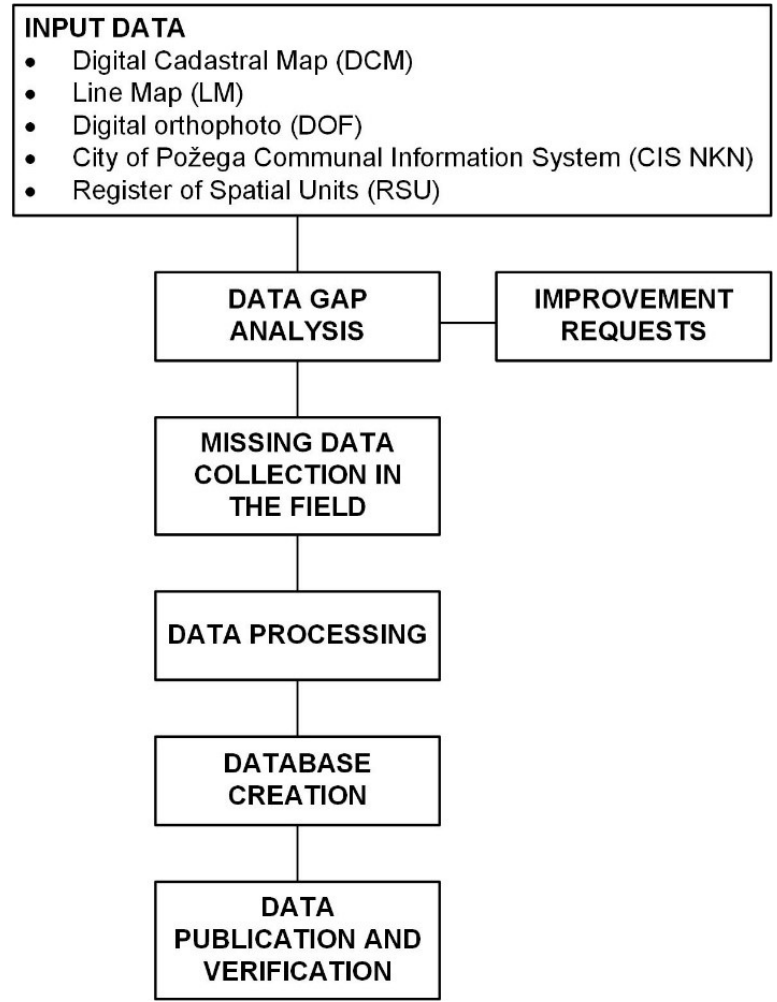

Figure 1. Schematic workflow diagram representing research study methodology

\subsection{Study area}

The study area was located within the district of the City of Požega, whole administrative area of the city that includes a large number of surrounding suburbs and smaller villages (Figure 2). Požega is a city in western Slavonia, in eastern part of Croatia, with a total population of 26,248 according to 2011 census. It is the administrative centre of the Požega-Slavonia County. The city is located at $45.34^{\circ} \mathrm{N}$ and $17.68^{\circ} \mathrm{E}$ at $152 \mathrm{~m}$ above sea level in the fertile valley, which is framed by the Slavonian mountain ring Psunj, Papuk, Dilj and Krndija. This fertile valley has been important since the antiquity - its Roman name was Vallis Aurea, meaning "golden valley".

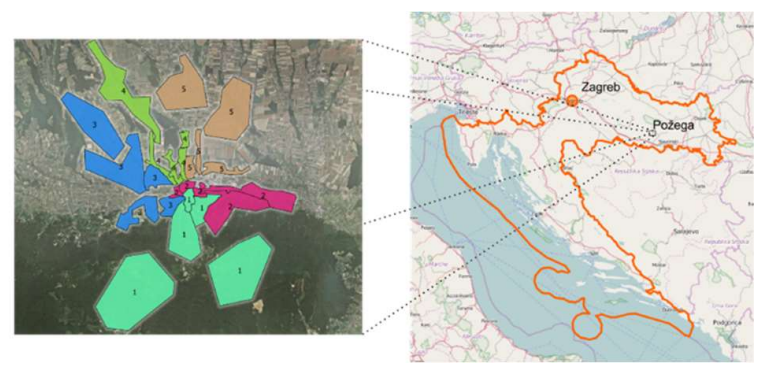

Figure 2. Location of City of Požega within Croatian territory and study area divided into five main field observation

\subsection{Input data}

In Croatia, the land administration system is based on two registers: Cadastre, under the responsibility of State Geodetic Administration (SGA) and Land Book which is under the responsibility of Local Courts. According to the law, the real estate consists of a land parcel including everything that is relatively permanently connected to it over and under its surface (Official Gazette, 16/2007). Real estate is registered in land and real estate cadastre, and the rights on them are realized by registering in the land book. Unfortunately, about $70 \%$ of cadastral maps in official use today were initially made by graphic surveys (Roić, 2012). Very often situation in the registers does not correspond to the real situation in the field. Registers however have correctly registered parcel boundaries as well as the registered owners, but some main objects (e.g. houses) and majority of secondary objects (e.g. garages) are still unregistered. City of Požega as a local administrative unit consists of several cadastral municipalities. The majority of cadastral maps for cadastral municipalities in Požega were made by numeric surveys in 1970's and 1980's. In those digital cadastral plans objects coincide very well with satisfactory accuracy with objects from line map (those that exists in cadastral map). In addition, three cadastral municipalities have new map made from new cadastral survey using modern geodetic methods (classic terrestrial geodetic survey combined with GNSS methods and aerial photogrammetry base maps) - KO (Croatian Katastarska općinaCadastral municipality) Vidovci, KO Dervišaga and KO Novo Selo. In those municipalities, objects from cadastral map and from line map coincide almost $100 \%$.

Due to this, the line map data product was used as input base layer for geographic and geometric identification of the buildings in the study area. Line map (LM) (Croatian: linijska karta) is a digital product which was used in the pilot realized as a part of Croatian-Norwegian funded project CRONO-GIP (Rožić et al, 2003). Purpose of Line Mapping was to reduce the field surveying during the Real Property Reambulation. Line Map dataset consists of following objects: buildings and other structures, land use and legal regimes. In order to complete the cadastral data, data about buildings and other structures were used and linked to cadastral parcels data and related information. Data from City of Požega Communal Information System (CIS) (Croatian: KOMIS) consisted from database export provided in Excel file (NKN). Each row contained information about the real estate, owner, address, billing address, area of property and the amount of utility charges. Addresses were not formatted accordingly to the spatial units' address records, which caused 
some problems in joining the official data to City of Požega Communal Information System data.

Part of the Register of Spatial Units (RSU), which is developed and maintained by the SGA, is the address register, which provides spatial representation of Street Names and House Numbers. There is an ongoing project which will develop new address register (Liker Božičević and Obad et al, 2015), defining the attributes and their domains, which will be more suitable for automatic data processing. However, the data was formatted using the old address model, which is basically formatted as points with some attribute data. Other parts of the RSU are administrative borders registers: register of regional selfgovernment units - counties, register of settlements, register of cadastral municipalities, and register of postal delivery areas. Digital orthophoto (DOF) was used as a base map. Majority of the input data - digital cadastral plans, RSU, LM for objects, and DOF datasets were provided by SGU for the study purposes.

\subsection{Data collection}

Data were collected by five teams formed by students from the faculty of geodesy in Zagreb, Croatia, that participated at the summer students practice. Mobile GIS devices Trimble Juno 3B with integrated high sensitive GPS receiver with Real-time measurement accuracy 2-5 meters and integrated 5Mpix camera together with pre-installed mobile GIS software ESRI ArcPad were used. Customised form for creating and editing the feature attributes was developed using ArcPad Studio (Rusmore, 2002) and attached to the dataset created for observation points within individual surveying groups (Figure 3).

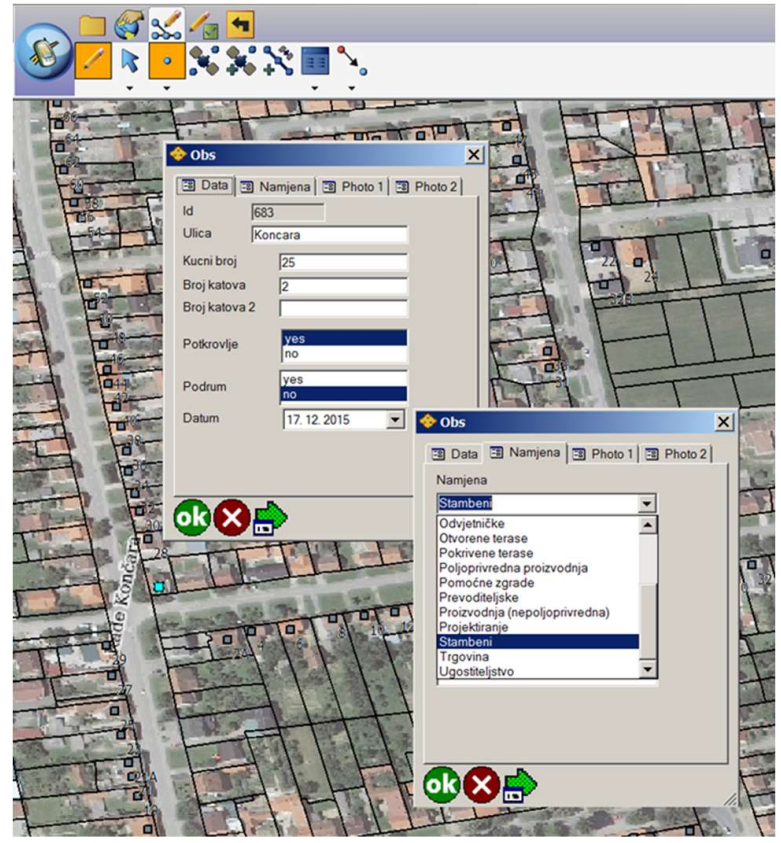

Figure 3. Snapshot of the form for collection and editing the feature attributes to the observed field measurement

The data model developed for field measurements (Table 1) comprised of basic object identification information as identifier (id), the name of the street (Ulica), the house number (Kucni broj), the number of floors (Broj katova), whether an object has a mansard (Potkrovlje), and whether an object has a basement (Podrum) that are detectable to be in use. The second group was devoted to identify the actual usage of the object by the predefined list of values originating from CIS NKN (e.g. residential, business, etc.). Since one object may have multiple usages, e.g. residential and business, multiple options were provided. The last step in the work plan was to take pictures of an object, which should represent the exact representation of the status described by the previous information.

\begin{tabular}{|c|c|c|c|c|}
\hline $\begin{array}{c}\text { Datas } \\
\text { et } \\
\text { name }\end{array}$ & $\begin{array}{l}\text { Geomet } \\
\text { ry type }\end{array}$ & $\begin{array}{l}\text { Attribute } \\
\text { name }\end{array}$ & $\begin{array}{l}\text { Data } \\
\text { type }\end{array}$ & $\begin{array}{c}\text { Multiplicit } \\
y\end{array}$ \\
\hline \multirow[t]{11}{*}{ Obs } & Point & $\begin{array}{l}\text { ID } \\
\text { (Identifier) }\end{array}$ & $\begin{array}{l}\text { Integer } \\
\text { (auto } \\
\text { increm } \\
\text { ent) }\end{array}$ & 1 \\
\hline & & $\begin{array}{l}\text { ULICA } \\
\text { (StreetName) }\end{array}$ & String & $0 . .1$ \\
\hline & & $\begin{array}{l}\text { KUCNI_BR } \\
\text { OJ } \\
\text { (HouseNumb } \\
\text { er) }\end{array}$ & Varchar & $0 . .1$ \\
\hline & & $\begin{array}{l}\text { KATA } \\
\text { (NumberFloo } \\
\text { rs) }\end{array}$ & Integer & $1 . .2$ \\
\hline & & $\begin{array}{l}\text { POTKROVL } \\
\text { JE (Mansard) }\end{array}$ & $\begin{array}{l}\text { Boolea } \\
n\end{array}$ & 1 \\
\hline & & $\begin{array}{l}\text { PODRUM } \\
\text { (Basement) }\end{array}$ & $\begin{array}{l}\text { Boolea } \\
n\end{array}$ & 1 \\
\hline & & $\begin{array}{l}\text { NAMJENA } \\
\text { (usageType) }\end{array}$ & String & $1 . .3$ \\
\hline & & $\begin{array}{l}\text { SLIKA } \\
\text { (photograph) }\end{array}$ & $\begin{array}{l}\text { FileNa } \\
\text { me }\end{array}$ & $1 . .2$ \\
\hline & & $\begin{array}{l}\text { NAPOMEN } \\
\text { A (note) }\end{array}$ & String & $0 . .1$ \\
\hline & & $\begin{array}{l}\text { DATUM } \\
\text { (date) }\end{array}$ & Date & 1 \\
\hline & & $\begin{array}{l}\text { GRUPA } \\
\text { (group) }\end{array}$ & Varchar & 1 \\
\hline
\end{tabular}

Table 1 Data model designed for field observations

Fourteen students were divided into five working groups, each having two Trimble Juno devices to perform data collection within the selected observation zone (Figure 2). The reference data as DOF address points dataset from RSU and objects features dataset from LM were preloaded into the working devices and used as background and supporting layers.

\subsection{Data processing}

The first step of the data processing stage was to include the observational data into the objects existing in the LM dataset. Attributes of each observed object feature from LM were extended by information collected in the field needed to update the newly calculated areas. The first step was realized using QGIS open source desktop GIS (Figure. 4).

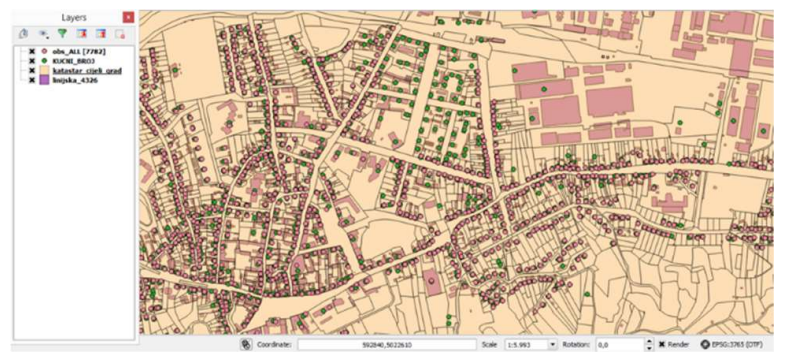

Figure 4. Integration of field observations with objects' features from LM dataset in QGIS 
For easier manipulation and calculations, the input datasets of cadastral parcels, LM updated by field observations and CIS NKN were imported into the PostgreSQL DBMS with PostGIS extension (Tsou and Smith, 2011). The first essential step was to join the non-spatial dataset of CIS NKN with two and half dimension (areas + number of levels) spatial dataset from the LM. The join was performed on the full addresses of objects available in both NKN and LM datasets. Since the address system in Croatia does not provide any unique identifier of an object within an administrative unit, the full address containing street name, house number and village name had to be used in order to avoid mismatching of the objects from different villages having the same street name and number. In addition, some of the addresses available in CIS NKN did not have proper entries, thus some semi-automatic regular expression based and manual corrections had to be applied. After the joining step, the nonspatial data were extended by geometries and further extended by new areas taking into account geometric areas, number of levels, areas coefficients defined for mansards and basements and other inputs. Another issue with demand for final result is that areas should be net areas (without areas of walls) For that reason, empiric coefficient was used to reduce area from geometries of object, and coefficients for some areas (basements and mansards) were applied according to Croatian law regulation, and City of Požega Council decision on communal tax. The secondary objects available in the LM dataset and located within the same polygon feature of a cadastral parcel were connected to nonspatial information assigned to the main object observed in the field.

\subsection{Data publication and verification}

In order to facilitate the data verification process and provide a presentation layer for the local government representatives and citizens, all relevant datasets were first published using standard geospatial web services as Web Map or View Service for data portrayal and Web Feature or Download Service (Kliment et al, 2012) for data manipulation. Both desktop and Web based access to final datasets is made available via QGIS desktop GIS and mapshup web client application (Gasperi et al, 2013) (Figure 5). Both applications access the data from common database underneath the deployed SDI.

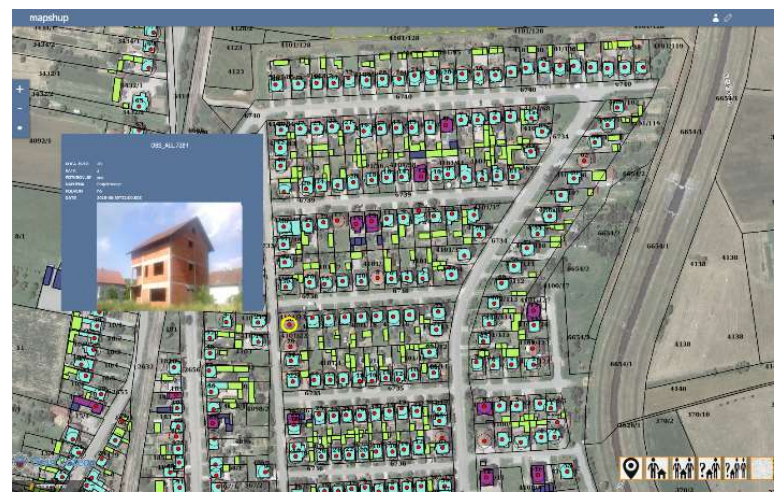

Figure 5. Web based mapshup viewer providing authorized portrayal access to field observation data, newly developed datasets of objects and cadastral parcels

The citizens, who are at the same time the communal tax payers can facilitate personalized access to the geographic features they own together with the newly calculated characteristics as areas based on geometric area, number of floors, existence of basement and / or mansard using the web browser. In addition, citizens can also see the data collected during the field campaign including the photograph of an object. Access to the data from both desktop and Web environment is restricted by username and password which could be generated for each citizen available in the original CIS NKN dataset and identified by OIB (Croatian: Osobni identifikacijski broj), a personal identification number.

\section{RESULTS AND DISCUSSION}

Overall dataset observed in the field (object polygon features available in the LM dataset) were represented by 7645 observations collected within a period of five working days (Figure 6). This number of objects was used for further processing in order to produce updated CIS NKN datasets restricted to those objects visited in the field.

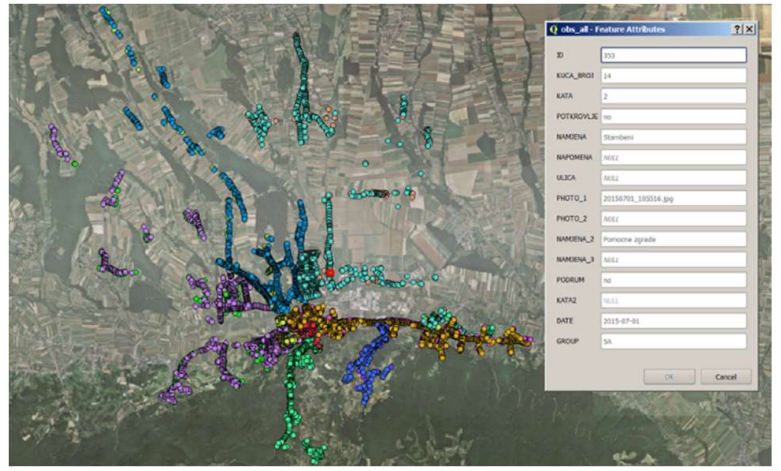

Figure 6. Geographic distributions of all observations collected by working groups and example of attributes for selected observation

The first step of data processing aimed at joining the geometry data from LM dataset updated by observations with input CIS $\mathrm{NKN}$ dataset. The joining process was based on the object's full address concatenated from a street name, house number and a town name (e.g. HRVATSKIH BRANITELJA 14 POŽEGA). The original CIS NKN dataset consisted of total amount of 11077 records, 7700 objects and 9715 owners. The dataset created after the join based on the full addresses consisted of 8396 records, 6724 objects and 7463 owners. The reason of decreased number of records was the inconsistency of addresses between RSU and CIS NKN that could not be fixed by automatic procedures and have to be fixed manually. The matching table (matching addresses between the old system and the new data collected) was created and will be extended and completed by local government employees in order to increase the final number of matched objects.

The next step was to divide the joined table to one dataset representing objects having single owner and one dataset for objects having multiple owners (Figure 7). The reason of this action was to calculate a coefficient of a share based on area division originating from CIS NKN dataset. The dataset representing the relation one object and one owner contained 5928 objects and the other one representing the relation one object and multiple owners had resulted in 796 objects.

Additionally, the processing step extended the total number of objects by assigning the owner to the secondary objects located with the same cadastral parcel boundaries as the main objects having the owner previously. This step resulted in other two datasets, one representing newly assigned secondary objects for those main objects having a single owner and one representing secondary objects sharing multiple owners of the main objects (Figure 7). The dataset aggregating data of one object having one owner resulted in 8259 objects and dataset of one object having multiple owners in 1089 objects. The total amount of objects 
updated and newly defined was 16072 , which represented $73 \%$ of the total amount of objects available in the LM dataset (21991 objects). Comparing to the input CIS NKN dataset, the result provided an increase of $45 \%$ in total amount of records defining the connection of objects and related owners. Nevertheless, this number will increase after the full address issues will be fixed in the matching table.

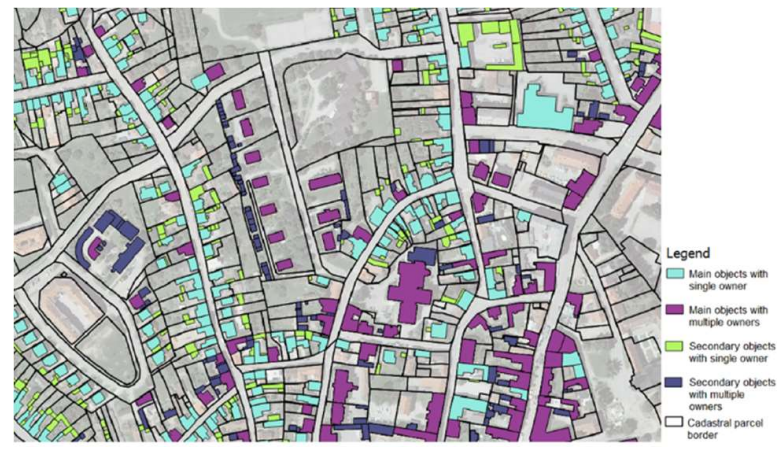

Figure 7. Preview of sample data from newly developed database categorized in four object datasets in QGIS desktop GIS

In order to avoid rough errors, some key issues needed to be resolved for final deliverable of newly developed database:

1. Object with area smaller than $5 \mathrm{~m} 2$ were erased

2. Records from NKN with usage code for unbuilt construction parcel were excluded from joining

3. Objects from LM dataset with certain range of usage codes were excluded from calculations due to City Council decision on exemption from payment on certain categories (religion objects, objects in City property, schools, etc.)

Due to spatial inconsistency between the parcels 'boundaries in the authoritative cadaster dataset and object polygons from LM dataset, the owner assignment for secondary objects applied spatial function determining if LM object centroid geometry is completely in polygon geometry of a cadastral parcel. In addition, some cadastral areas had the shift bigger what caused incorrect assignment. As example some secondary objects whose centroids have topologically fallen into e.g. a road parcel were not assigned to any owner, or assigned a wrong neighboring owner (Figure 8).

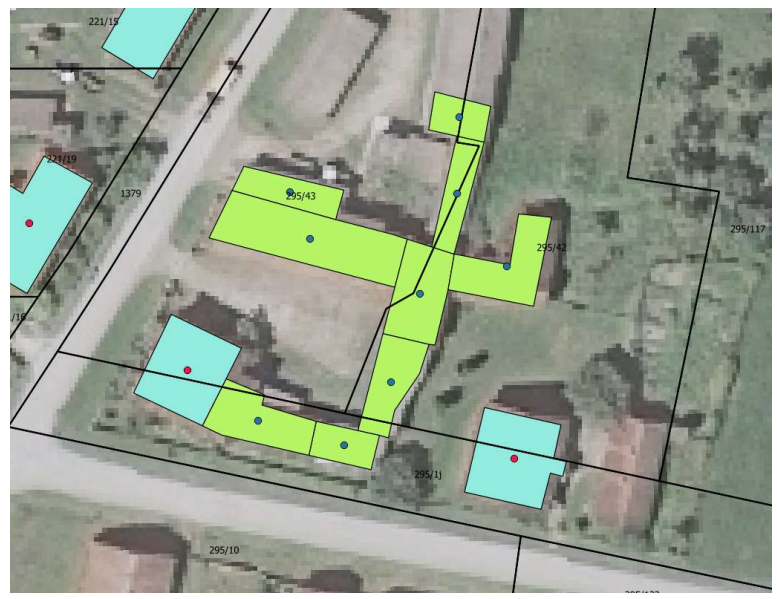

Figure 8. Example of spatial inconsistency of reference LM and cadastral data resulting in wrong or none owner assignment
These objects had to be fixed manually by moving the centroids into an appropriate parcel based on the owner of the main object and triggering the function assigning the ID of the parcel to those objects having their centroids within.

\subsection{Results in cadastral municipalities with cadastral maps made after year 2000 with new cadastral survey}

Within the cadastral municipalities (CM) KO Vidovci and $\mathrm{KO}$ Dervišaga the results provided the figures that are summarized in Table 2:

\begin{tabular}{|l|c|c|c|c|}
\hline \multicolumn{1}{|c|}{ CM } & $\begin{array}{c}\text { Objects } \\
\text { in NKN }\end{array}$ & $\begin{array}{c}\text { Objects } \\
\text { after the } \\
\text { project }\end{array}$ & $\begin{array}{c}\text { Overall } \\
\text { area }\end{array}$ & $\begin{array}{c}\text { Overall } \\
\text { area after } \\
\text { the project }\end{array}$ \\
\hline $\begin{array}{l}\text { KO } \\
\begin{array}{l}\text { Vidovci } \\
\text { KO } \\
\text { Dervišaga }\end{array}\end{array}$ & 547 & 1198 & 72549 & 80334 \\
& 301 & 749 & 32086 & 49320 \\
\hline
\end{tabular}

Table 2 Results in Požega's cadastral municipalities with cadastral maps made after year 2000 with new cadastral survey

In these cadastral municipalities there was no cases like described above (spatial inconsistency between the parcels 'boundaries in the authoritative cadaster dataset and object polygons from LM dataset). Additionally, there was not so many problems in dividing areas to owners of properties, which have more than one owner, since information on owners, and ownership ratios are up to date and can be easily found. Therefore, project calculations gave highly reliable results for these cadastral municipalities.

\subsection{Personalized viewer for data portrayal and verification}

In order to provide the citizens an easy way to preview and verify the new data about their properties, a personalized web based geospatial viewer was developed and made available via Internet (Figure 9). The main goal was to provide a possibility to check the quality of the data directly by property owners, thus the tax payers.

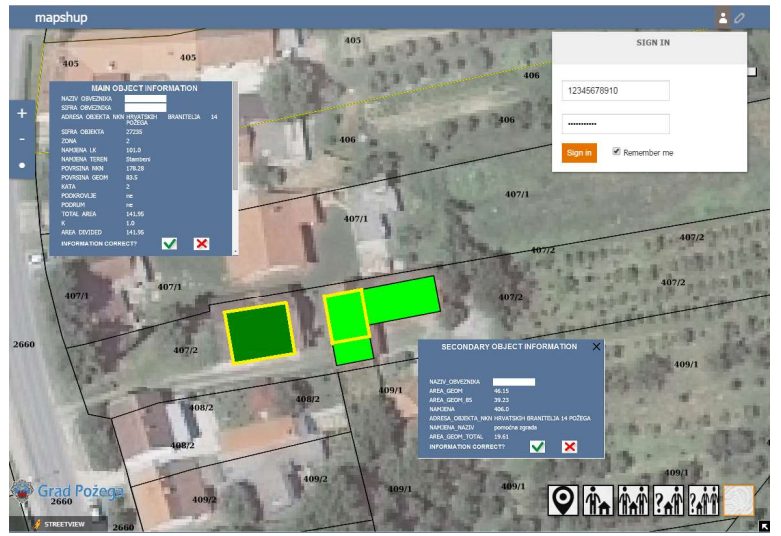

Figure 9. Example of spatial inconsistency of reference LM and cadastral data resulting in wrong or none owner assignment

Each tax payer can log into the personalized portal, which automatically zooms to the extent based on his / her objects available in the newly created datasets. Information about each main object contain data about the owner name, full address, usage type (e.g. residential building), area from original CIS NKN dataset, newly calculated area based on geometry from the LM dataset, number of floors, mansard and basement information observed in the field, the total area, coefficient and divided area for multiple owner's objects. Narrower amount of information is 
provided for secondary objects as area calculated from geometry, usage type (e.g. ancillary building), full address assigned, and the total area used for tax calculations. Total areas represent the final amount of square metres after applying all the reduction coefficients for firstly the net areas (0.85), areas of basements or mansards (0.50) and secondary objects $(0.50)$. The coefficients are applied on the area calculated from the objects geometry. All this information provided to the citizens can be verified by accepting the content of the information window. Each accepted feature is flagged in the database as valid and thus can proceed for the new tax calculation based on new total area. On the other hand, those objects identified as having incorrect information are flagged as invalid and further investigation is required. Either the local government employee is send to the field or the owner is invited to the city office for further explanations and clarifications. These objects are in the queue for new tax calculation until the issues are resolved.

The main reason of using citizens as VGI to verify the quality of the data was lack of resources available in the local government that could not perform the check of almost 20 thousand objects within an area of $80 \mathrm{~km}^{2}$ in a realistic way.

\section{CONCLUSIONS}

The time brings changes, and awareness of the need to understand interdependencies of environmental and social phenomena. Today, just the knowledge of availability of spatial data is not enough, neither for city employees nor for ordinary citizens. They want and they need more spatial data needed for sophisticated processing and analysis models that can turn data and information into insight and intelligent action. This is the way to support and empower local government implementing the e-governance processes on the municipality level.

In this paper we presented the methodology to integrate the data collected following participatory approaches with authoritative datasets made available by national bodies responsible for geospatial data into a common platform based on SDI principles. In addition, we proposed to use VGI principles in order to run data validation processed controlled by citizens, the property owners who are obliged to pay the tax. With this respect we developed personalized web based access to the newly developed datasets of object features and related characteristics. The verification process has been launched recently and is expected to end in next two months. The research project resulted in a database containing valuable information about buildings within the district of city of Požega and surrounding suburbs, which represents a valuable source for the developing local SDI.

\section{ACKNOWLEDGEMENTS}

This work was supported by City of Požega, and Croatian Science Foundation under the project 7714 "DEMLAS" and by NEWLEFPRO project of the Government of the Republic of Croatia and the Ministry of Science, Education and Sport cofinanced through the Marie Curie grant agreement no. 291823. Horticulture and Landscape Engineering Faculty of the Slovak University of Agriculture provided the professional instruments used for the field works.

\section{REFERENCES}

Coleman, D. J., Georgiadou, Y., \& Labonte, J. (2009). Volunteered geographic information: The nature and motivation of produsers. International Journal of Spatial Data Infrastructures Research, 4(1), 332-358.
Erik de Man, W. H. (2006). Understanding SDI; complexity and institutionalization. International Journal of Geographical Information Science, 20(3), 329-343.

Gasperi, J., Peyrega, C., Dinot, S., Boileau, Q., Manin, A., \& Heurteaux, V. (2013, April). Web Processing Service for assisted land cover classification. In: EGU General Assembly Conference Abstracts (Vol. 15, p. 6087).

George, E. S. (2006). Positioning higher education for the knowledge based economy. Higher Education, 52(4), 589-610.

Goodchild, M. F. (2007). Citizens as sensors: the world of volunteered geography. GeoJournal, 69(4), 211-221.

Kliment, T., Tuchyňa, M., \& Kliment, M. (2012). Methodology for conformance testing of spatial data infrastructure components including an example of its implementation in Slovakia. Slovak Journal of Civil Engineering, 20(1), 10-20.

Liker Božičević, M., Obad, T. (2015): Adresni registar. In: National Spatial Infrastructure Days 2015, 15.-16. October 2015, Faculty of Geodesy, Zagreb.

Miranda, T. S., Lisboa Filho, J., Souza, W. D., Silva, O. C., \& Davis Junior, C. A. (2011, September). Volunteered geographic information in the context of local spatial data infrastructures. In: Urban Data Management Symposium, pp. 123-138.

Narodne novine (Official Gazette): Law on State Survey and the Real Property Cadastre, 16/2007.

Nebert, D. D. (2009). The spatial data infrastructure cookbook.

Roić, M. (2012). Land Information Management: Cadastre (Upravljanje zemljišnim informacijama: katastar). Manualia Universitatis studiorum Zagrabiensis, Faculty of Geodesy University of Zagreb, 2012.

Rožić, N., Lemajić, S., \& Rapaić, M. (2003, October). CroatianNorwegian geoinformation project. In: Proceedings of the ISPRS WG VI/3 Workshop (pp. 224-227).

Rusmore, M. E., (2002): Teaching Advanced Field Mapping on Hand - Held Computers. In: 2002 Denver Annual Meeting.

Šiško, D., Veselić Bruvo, J., \& Batić, S. (2012). Zagreb SDI-Tool for Sustainable Spatial Management. In: INSPIRE Conference 2012 .

Tsou, M. H., SMITH, J. (2011) Free and Open Source software for GIS education. In: Un-published White Paper Prepared for the GeoTech Center. Louisville, USA: NGTCE. 18 p 